\title{
Cell cycle regulation of astrocytes by extracellular nucleotides and fibroblast growth factor-2
}

\author{
Joseph T. Neary, Yuan Kang \& You-Fang Shi \\ Research Service, Miami VA Medical Center, Departments of Pathology and Biochemistry \& Molecular Biology, and \\ Neuroscience Program, University of Miami School of Medicine, Miami, Florida, USA
}

Received 27 August 2004; accepted in revised form 8 April 2005

Key words: astrocytes, cell cycle, CNS injury, ERK, extracellular ATP, gliosis, P2 purinergic receptors, proliferation

\begin{abstract}
Extracellular ATP enhances the mitogenic activity of fibroblast growth factor-2 (FGF2) in astrocytes, but the molecular mechanism underlying this synergistic interaction is not known. To determine whether the potentiating effect of extracellular ATP involves cell cycle control mechanisms, we have measured the expression of cyclins that are induced in different phases of the cell cycle in primary cultures of rat cortical astrocytes. We found that ATP potentiated the ability of FGF2 to stimulate expression of cyclin D1, a regulator of cell cycle entry, as well as cyclin A, a regulator of DNA replication. Because FGF2 and P2 purinergic receptors are coupled to extracellular signal regulated protein kinase (ERK), a key member of a signaling cascade that regulates proliferation, we also investigated the role of ERK in regulating cyclin expression induced by FGF2 and ATP. We found that the potentiating effect of ATP on cyclin expression was significantly reduced by U0126, an inhibitor of MEK, the upstream activator of ERK. P2 receptor agonist studies revealed that UTP enhanced FGF2-induced cyclin expression and mitogenesis whereas 2-methylthioADP was ineffective. By contrast, 2',3'-O-(4-benzoyl)-benzoyl-ATP markedly inhibited FGF2-induced mitogenesis. Consistent with opposing effects of P2Y and P2X receptors on mitogenesis, UTP stimulated a transient activation of ERK whereas BzATP stimulated a more sustained ERK signal. These findings suggest that signaling by P2Y receptors, most likely of the purine/pyrimidine subtype, enhance the ability of FGF2 to stimulate entry into a new cell cycle, as well as DNA replication, by an ERK-dependent mechanism, whereas signaling by P2X receptors, possibly the P2X7 subtype, inhibits FGF2-induced mitogenesis in astrocytes. Interactions between P2Y, P2X and polypeptide growth factor signaling pathways may have important implications for CNS development as well as injury and repair.
\end{abstract}

\section{Introduction}

Although normally quiescent, astrocytes in the adult nervous system have the ability to proliferate. In particular, astrocyte proliferation in adult brains has been observed after breakdown of the blood brain barrier such as occurs after stab wounds and head trauma [1-6]. In addition, astrocytes can act as neural stem cells in the normal and regenerating brain [7]. Studies of cell cycle regulatory proteins in astrocytes have demonstrated that addition of epidermal growth factor (EGF) to confluent astrocytes resulted in the formation of multiple cell layers and elevated levels of cyclin D1 [8] which is induced in response to mitogenic signals. Cell cycle entry and progression is regulated by the expression of proteins termed cyclins [9]. Cyclin levels are low in quiescent cells but increase

Correspondence to: Dr Joseph T. Neary, PhD, Research Service 151, VA Medical Center, 1201 NW 16th Street, Miami, FL 33215, USA. Tel: +1305-3244455; Fax: +1-305-5753126; E-mail: jneary@med.miami.edu in response to mitogenic growth factors during distinct phases of the cell cycle. For example, cyclin D1 is increased during entry and progression through G1 phase while cyclin $\mathrm{A}$ is increased in $\mathrm{S}$ phase during which time DNA is replicated. The expressed cyclins bind to and activate enzymes termed cyclin-dependent protein kinases, thereby leading to changes in phosphorylation of key proteins that control various phases of the cell cycle. It was suggested that changes in the expression of cell cycle regulatory proteins may be involved in the increased proliferation observed in the gliosis that occurs after injury to the adult CNS [8].

Fibroblast growth factor-2 (FGF2) is increased after CNS injury (e.g., [10]) and can stimulate the gliotic response in cultured astrocytes (e.g., [11]) and in vivo [12]. When applied to mechanically wounded astrocytes, FGF2 enhanced proliferation, stellation and cell migration [13]. ATP is also released upon tissue injury and may contribute to gliosis [14]. When ATP or other nucleotide receptor agonists were added to astrocytes in culture, key hallmarks of gliosis were observed, i.e., increases in proliferation, 
stellation and glial fibrillary acidic protein (GFAP) [15-17]. In vivo, GFAP and astrocyte proliferation were increased after infusion of an ATP analog into rat brain [18]. These effects of ATP were blocked by nucleotide receptor antagonists, thereby indicating that P2 purinergic receptors mediate the gliotic actions of ATP in vivo.

Extracellular ATP can enhance the mitogenic activity of polypeptide growth factors in several cell types (reviewed in [19]). In astrocytes, we found that extracellular ATP markedly potentiated FGF2-induced mitogenesis [20]. However, little is known about the interactive effects of extracellular nucleotides and growth factors on cell cycle regulatory mechanisms, particularly in cells of the central nervous system. Here we report for the first time that extracellular ATP and UTP enhance FGF2-induced expression of cyclins involved in cell cycle entry and progression through the G1 and S phases of the cell cycle by a mechanism involving extracellular signal regulated protein kinase (ERK). We also demonstrate that BzATP inhibits the ability of FGF2 to stimulate mitogenesis, thereby suggesting that $\mathrm{P} 2 \mathrm{Y}$ and $\mathrm{P} 2 \mathrm{X}$ receptors exert opposing effects on FGF2-induced proliferation in astrocytes.

\section{Materials and methods}

\section{Cell culture and treatment}

Primary cultures of astrocytes were obtained from neonatal rat (Fischer) cerebral cortices as previously described [20]; the experimental procedure was approved and monitored by the Animal Studies Subcommittee at the Miami VA Medical Center and the Animal Care and Use Committee, University of Miami School of Medicine. Cells were seeded at densities of 1.5 and 4 million cells per $60 \mathrm{~mm}$ and $100 \mathrm{~mm}$ dishes, respectively; cells were not replated before use. At least $95 \%$ of the cell population was astrocytes, as determined by staining with cell-specific markers [20]. Experiments were conducted with 4-5-weekold cultures. Prior to treatment, cells which had been maintained in Dulbecco's modified Eagle's medium (DMEM) containing $10 \%$ horse serum were shifted to the quiescent phase by incubation in serum-free DMEM for $48 \mathrm{~h}$. Stock solutions of ATP and other nucleotides (Sigma Chemical Co., St. Louis, MO) and FGF2 (recombinant human FGF2; R\&D Systems, Minneapolis, MN) were divided into singleuse aliquots and stored at $-80{ }^{\circ} \mathrm{C}$.

\section{Immunoblotting}

Cyclin expression was measured by immunoblotting. After treatment with FGF2 and/or nucleotides, cells were rinsed twice in ice-cold PBS and lysed in a buffer containing $20 \mathrm{mM}$ Tris, $\mathrm{pH}$ 7.0, $0.27 \mathrm{M}$ sucrose, $1 \mathrm{mM}$ EDTA, $1 \mathrm{mM}$ EGTA, $50 \mathrm{mM} \mathrm{NaF}, 1 \mathrm{mM}$ dithiothreitol, $1 \mathrm{mM}$ sodium orthovanadate, $10 \mathrm{mM}$ sodium $\beta$-glycerophosphate, $5 \mathrm{mM}$ sodium pyrophosphate, $1 \mu \mathrm{g} / \mathrm{ml}$ pepstatin $\mathrm{A}, 4 \mu \mathrm{M}$ leupeptin, $0.3 \mathrm{U} / \mathrm{ml}$ aprotinin, $100 \mu \mathrm{g} / \mathrm{ml} \mathrm{4-(2-aminoethyl)-}$ benzenesulfonylfluoride (AEBSF) and 1\% NP-40. Protein concentrations were determined by the Coomassie micro method (Bio Rad Laboratories, Hercules, CA) with bovine serum albumin as standard. Lysates containing equal amounts of protein $(50 \mu \mathrm{g})$ were subjected to SDSpolyacrylamide gel electrophoresis [21] using $11 \%(\mathrm{w} / \mathrm{v})$ acrylamide and transferred to nitrocellulose filters with a Genie electrophoretic blotter (Idea Scientific Inc., Minneapolis, MN) for $1 \mathrm{~h}$ at $12 \mathrm{~V}$ in a transfer buffer containing $25 \mathrm{mM}$ Tris, $192 \mathrm{mM}$ glycine and 20\% (v/v) methanol. Membranes were incubated with a blocking solution containing $20 \mathrm{mM}$ Tris, pH 7.7, $137 \mathrm{mM} \mathrm{NaCl}, 0.1 \%$ $(\mathrm{v} / \mathrm{v})$ Tween 20 (TTBS) and 5\% (w/v) nonfat dry milk for $1 \mathrm{~h}$ at room temperature, rinsed in TTBS, and then incubated for $1 \mathrm{~h}$ at room temperature with specific antibodies (anti-cyclin D1, 1/500 dilution; anti-cyclin A, 1/200 dilution; or $\beta$-actin, 1/50,000 dilution) in blocking solution containing $0.02 \%$ sodium azide. Polyclonal antibodies recognizing cyclin D1 (sc-718) and cyclin A (sc-596) were purchased from Santa Cruz Biotechnology, Santa Cruz, CA, and monoclonal antibodies recognizing $\beta$-actin were obtained from Sigma Chemical Co., St. Louis, MO. Following three rinses in TTBS, membranes were incubated for $1 \mathrm{~h}$ at room temperature with peroxidase-conjugated donkey anti-rabbit or anti-mouse IgG (Amersham Pharmacia Biotech, Piscataway, NJ) diluted 1/5000 in blocking solution. Membranes were washed three times in TTBS, and cyclin D1, cyclin A and $\beta$-actin were detected by ECL (SuperSignal West Femto Maximum Sensitivity Substrate; Pierce Biotechnology, Rockford, IL) with Kodak Biomax film (Eastman Kodak Company, Rochester, NY). Films were scanned and densitometrically analysed using Molecular Analyst Software (Bio-Rad Laboratories, Hercules, CA). In some cases, membranes were blocked and probed according to the manufacturer's instructions for analysis with an Odyssey Infrared Imaging System (Li-Cor Biosciences, Lincoln, NB) using Alexa Fluor 680-labeled anti-rabbit IgG (Molecular Probes, Eugene, OR) or IRDye 800 labeled antimouse IgG (Rockland Immunochemicals, Gilbertsville, PA) secondary antibodies. For quantification, cyclin/actin ratios were measured to correct for minor loading differences. To compare levels of cyclin expression among different experiments, data were calculated as fold stimulation compared to FGF2.

\section{DNA synthesis}

${ }^{3} \mathrm{H}$-Thymidine incorporation was measured as previously described [20]. Data were expressed as $\mathrm{cpm} / \mathrm{mg}$ protein. Protein concentrations were determined by the modified Lowry procedure with bovine serum albumin as standard [22].

\section{ERK1/2 phosphorylation}

Quiescent cultures were treated at $37^{\circ} \mathrm{C}$ with vehicle, UTP or BzATP for the times indicated. Cells were lysed in SDS sample buffer [21] and protein concentrations determined by the modified Lowry procedure [22]. Cell lysates, containing $35 \mu \mathrm{g}$ of protein, were subjected to SDS-PAGE 
(11\% acrylamide gel) and Western Blot analysis was performed using specific phospho-ERK monoclonal antibody (Thr202/Tyr204; 1/5000 dilution) from Cell Signaling Technology, Beverly, MA, and total-ERK polyclonal antibody (1/5000 dilution) from Santa Cruz Biotechnology, Santa Cruz, CA. For visualization, membranes were blocked and probed according to the manufacturer's instructions for analysis with an Odyssey Infrared Imaging System (Li-Cor Biosciences, Lincoln, NB) using IR-Dye 800 conjugated anti-mouse IgG (1/5000 dilution) and IRDye 700DX conjugated anti-rabbit IgG (1/10,000 dilution) obtained from Rockland Immunochemicals, Gilbertsville, PA. Intensities of phospho-ERK1/2 and total ERK1/2 bands were quantified and ratios of phospho-ERK1/2/total ERK1/2 were calculated and compared to control (vehicletreated) cultures.

\section{Statistical analyses}

Data were analyzed by Student's $t$-test for two groups or repeated measures ANOVA for multiple groups followed by post-hoc comparisons (Bonferroni test) using an Instat software package (GraphPad Software, San Diego, CA, USA). Replicate experiments were conducted with cultures from different seedings.

\section{Results}

\section{Expression of cyclin D1 and cyclin $A$}

To determine whether interactive effects of extracellular ATP and FGF2 involve cell cycle regulation, we measured the expression of cyclins that are induced in different phases of the cell cycle. Quiescent, primary cultures of rat cortical astrocytes were treated with ATP $(100 \mu \mathrm{M})$, FGF2 $(25 \mathrm{ng} / \mathrm{ml})$ or a combination of ATP and FGF2. Expression of cyclin D1, a cell cycle regulatory protein induced in G1 phase in response to stimulation by growth factors, was measured by immunoblotting and identified by co-migration with a positive control (Figure 1A). Blots were also probed with anti-actin antibodies as a loading control. Cyclin D1 expression was stimulated by FGF2 (Figure 1A). At the level of detection, ATP alone was without effect. However, when cells were treated with both ATP and FGF2, the expression of cyclin D1 was potentiated. An analysis of variance revealed an overall significant difference among the groups and planned comparisons revealed that the ATP + FGF2 group was significantly different $(P<0.05)$ from the FGF2 group (Figure 1B). These results suggest that extracellular ATP can enhance the ability of FGF2 to stimulate entry of astrocytes into the cell cycle.

To determine whether extracellular ATP also enhances the effect of FGF2 on entry and progression of astrocytes through S phase, cyclin A expression was measured. Quiescent, primary cultures of rat cortical astrocytes were treated with ATP $(100 \mu \mathrm{M})$, FGF2 $(25 \mathrm{ng} / \mathrm{ml})$ or a combination of ATP and FGF2. Cyclin A expression was
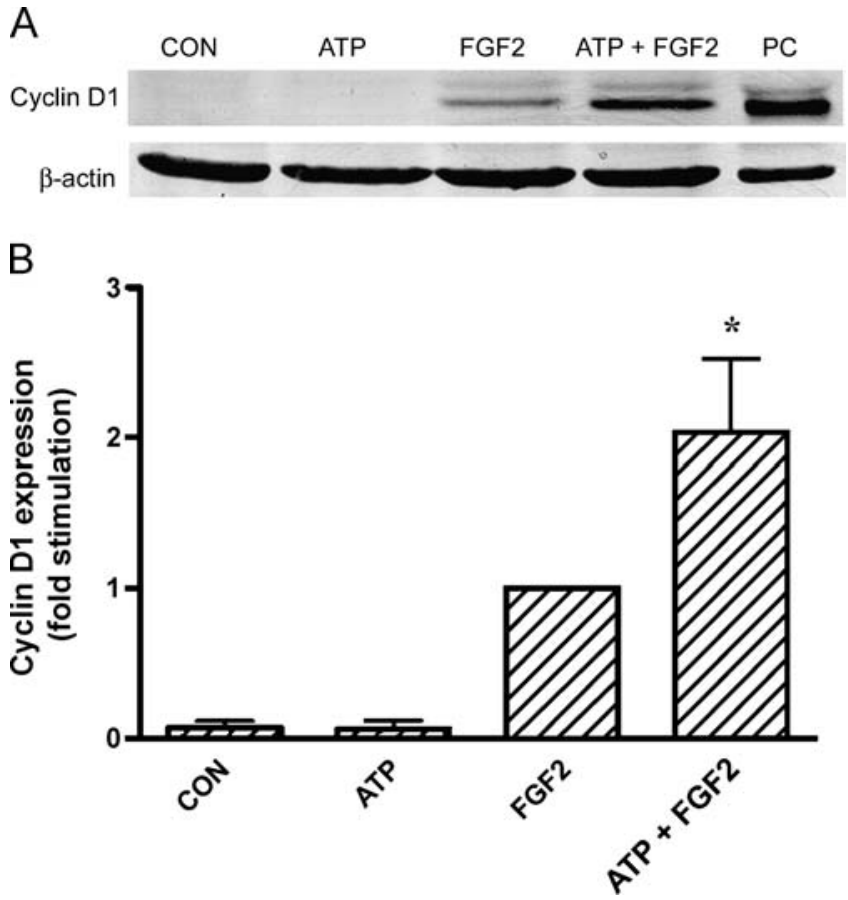

Figure 1. Extracellular ATP enhances cyclin D1 expression induced by FGF2. A) Quiescent, primary cultures of rat cortical astrocytes were treated with ATP $(100 \mu \mathrm{M})$, FGF2 $(25 \mathrm{ng} / \mathrm{ml})$ or a combination of ATP and FGF2 for $20 \mathrm{~h}$. Lysates were subjected to SDS-PAGE, and cyclin D1 expression was measured by immunoblotting. Cyclin D1 was identified by co-migration with a positive control (PC). Blots were also probed with anti-actin antibodies as a loading control. ATP potentiated the ability of FGF2 to stimulate expression of cyclin D1. B) Results (mean \pm SEM) from three independent experiments in which astrocyte cultures were treated as described in (A). FGF2-induced cyclin D1 expression was significantly enhanced by extracellular ATP $(* P<0.05)$.

measured by immunoblotting and identified by co-migration with a positive control (Figure 2A). Blots were probed with anti-actin antibodies as a loading control. We found that ATP also potentiated the ability of FGF2 to stimulate expression of cyclin A (Figure 2A). An analysis of variance from group data revealed an overall significant difference and planned comparisons revealed that the ATP + FGF2 group was significantly different $(P<0.01)$ from the FGF2 group (Figure 2B). These results indicate that extracellular ATP also enhances the ability of FGF2 to induce the expression of cyclin $\mathrm{A}$, a protein involved in entry and progression through the $\mathrm{S}$ phase, the DNA replication stage of the cell cycle.

\section{Enhancement of FGF2-induced cyclin expression by extracellular ATP involves ERK signaling}

To investigate the mechanism by which extracellular ATP enhances cyclin expression induced by FGF2, we focused on ERK, a key member of a signaling pathway that regulates mitogenesis [23]. Both FGF2 and extracellular ATP stimulated ERK in rat cortical astrocytes [24-26], and blockade of the ERK cascade inhibited ATP-induced mitogenesis in astrocytes [27]. To determine whether the potentiation of FGF2-induced cyclin D1 expression by extracellular ATP in primary cultures of 
A

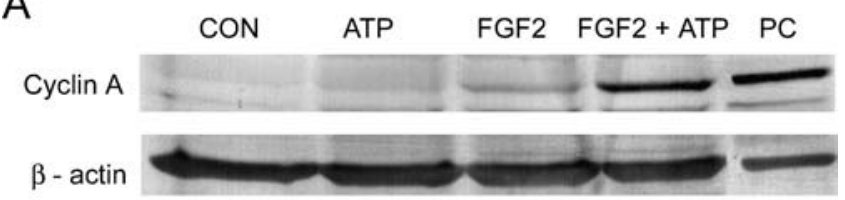

B

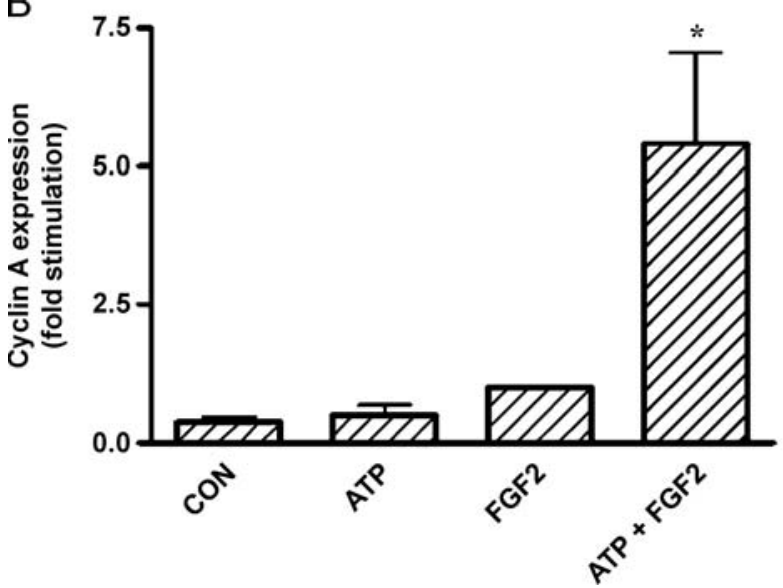

Figure 2. Extracellular ATP enhances cyclin A expression induced by FGF2. (A) Quiescent, primary cultures of rat cortical astrocytes were treated with ATP $(100 \mu \mathrm{M})$, FGF2 $(25 \mathrm{ng} / \mathrm{ml})$ or a combination of ATP and FGF2 for $20 \mathrm{~h}$. Lysates were subjected to SDS-PAGE, and cyclin A expression was measured by immunoblotting. Cyclin A was identified by co-migration with a positive control (PC). Blots were also probed with anti-actin antibodies as a loading control. ATP potentiated the ability of FGF2 to stimulate expression of cyclin A. (B) Results (mean \pm SEM) from four independent experiments in which astrocyte cultures were treated as described in (A). FGF2-induced cyclin A expression was significantly enhanced by extracellular ATP $(* P<0.01)$

astrocytes was mediated by ERK, we utilized U0126, an inhibitor of MEK, the upstream activator of ERK. U0126 $(10 \mu \mathrm{M})$ was added to quiescent, primary cultures of rat cortical astrocytes $30 \mathrm{~min}$ prior to treatment with ATP $(100 \mu \mathrm{M})$, FGF2 $(25 \mathrm{ng} / \mathrm{ml})$ or a combination of ATP and FGF2. When the ERK cascade was blocked, the upregulation of cyclin D1 by FGF2 was significantly inhibited $(P<0.05)$ (Figures $3 \mathrm{~A}$ and $\mathrm{B})$. Importantly, blockade of the ERK cascade also significantly inhibited the ability of extracellular ATP to enhance cyclin D1 expression induced by FGF2 $(P<0.001)$ (Figures 3A and B).

Because blockade of the ERK cascade inhibited cyclin D1 expression induced by FGF2 and extracellular ATP, and because cyclin A is expressed subsequent to cyclin D1, we reasoned that inhibition of the ERK cascade should also reduce cyclin A expression. To test this, U0126 $(10 \mu \mathrm{M})$ was added to quiescent, primary cultures of rat cortical astrocytes $30 \mathrm{~min}$ prior to treatment with ATP $(100 \mu \mathrm{M})$, FGF2 $(25 \mathrm{ng} / \mathrm{ml})$ or a combination of ATP and FGF2 (Figures 4A and B). We found that blockade of the ERK cascade significantly inhibited the expression of cyclin A induced by FGF2 $(P<0.05)$ as well as the potentiation of FGF2-induced cyclin A by extracellular ATP $(P<0.001)$. These findings indicate that the ERK cascade plays an important role in mediating the co-mitogenic activity of extracellular ATP.
A
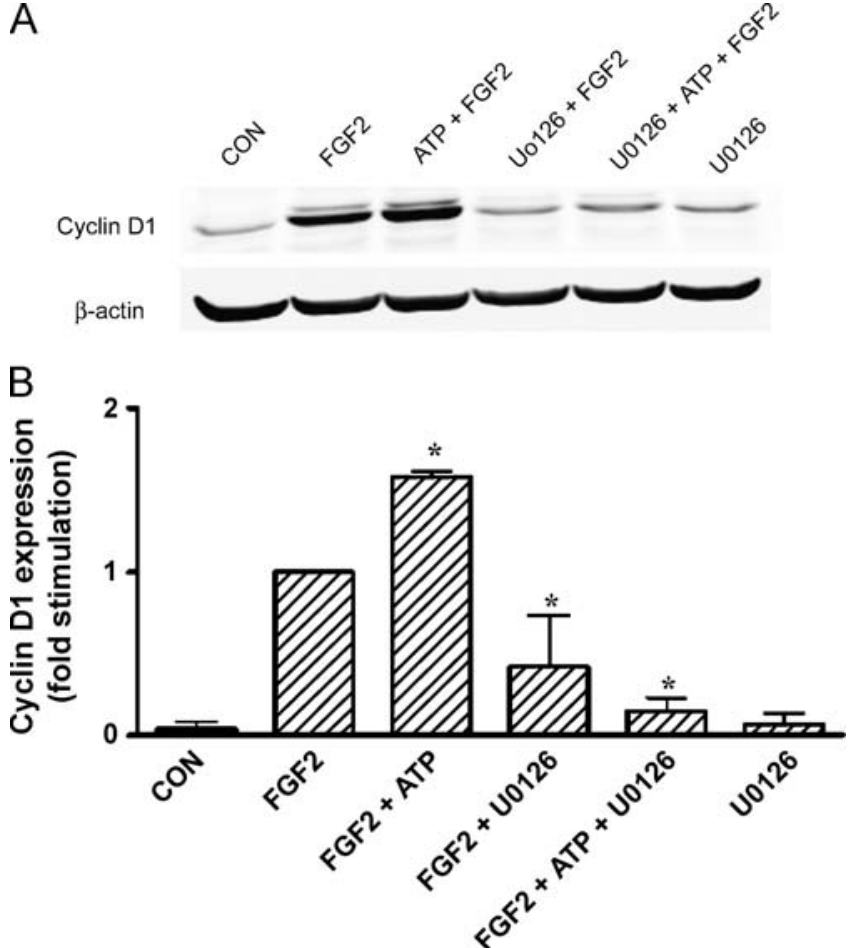

Figure 3. ERK mediates the enhancement of cyclin D1 expression induced by FGF2 and extracellular ATP. To determine whether the potentiation of FGF2-induced cyclin D1 expression by extracellular ATP was mediated by ERK, U0126 ( $10 \mu \mathrm{M}, 30 \mathrm{~min}$ ), an inhibitor of MEK, the upstream activator of ERK, was added to quiescent, primary cultures of rat cortical astrocytes prior to treatment with ATP $(100 \mu \mathrm{M})$, FGF2 ( $25 \mathrm{ng} / \mathrm{ml}$ ) or a combination of ATP and FGF2 for $20 \mathrm{~h}$. (A) Lysates were subjected to SDS-PAGE, and cyclin D1 expression was measured by immunoblotting. (B) Results (mean \pm SEM) from three independent experiments in which astrocyte cultures were treated as described in (A). Blockade of the ERK cascade significantly inhibited the expression of cyclin D1 induced by FGF2 as well as the potentiation of FGF2-induced cyclin D1 by extracellular ATP (*: FGF2 + ATP compared to FGF2, $P<$ 0.05; FGF2 + U0126 compared to FGF2, $P<0.05$; FGF2 + ATP + U0126 compared to FGF2 + ATP, $P<0.001)$.

$P 2 Y$ and $P 2 X$ receptors exert opposing effects on FGF2induced mitogenesis

To investigate the type(s) of $\mathrm{P} 2$ purinergic receptors involved in the synergistic effects of extracellular ATP on cyclin expression induced by FGF2, we conducted studies with UTP and 2methylthioADP (2MeSADP), agonists of $\mathrm{P} 2 \mathrm{Y}_{2 / 4}$ and $\mathrm{P} 2 \mathrm{Y}_{1}$ receptors, respectively. Quiescent astrocyte cultures were treated with FGF2 $(25 \mathrm{ng} / \mathrm{ml})$, ATP $(100 \mu \mathrm{M})$, UTP $(100 \mu \mathrm{M}), 2 \mathrm{MeSADP}(10 \mu \mathrm{M})$ or a combination of FGF2 and each nucleotide. We found that cyclin A expression was enhanced by combined treatment of astrocytes with FGF2 and UTP (Figure 5A). By contrast, 2MeSADP was ineffective. Similar results were obtained for cyclin D1. To extend these studies, we investigated the effects of UTP and 2MeSADP on FGF2-induced astrocyte mitogenesis. We found that FGF2-induced DNA synthesis was also potentiated by UTP, but not by 2MeSADP (Figure 5B). Thus, these studies were consistent with those of cyclin A and D1 and suggested a role for $\mathrm{P}_{2} \mathrm{Y}_{2 / 4}$ receptors. To investigate further the type of $\mathrm{P} 2$ receptor 
A

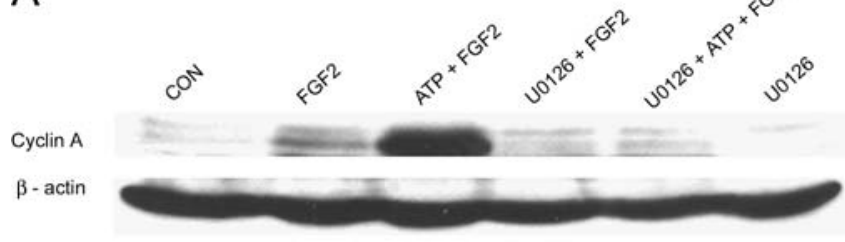

B

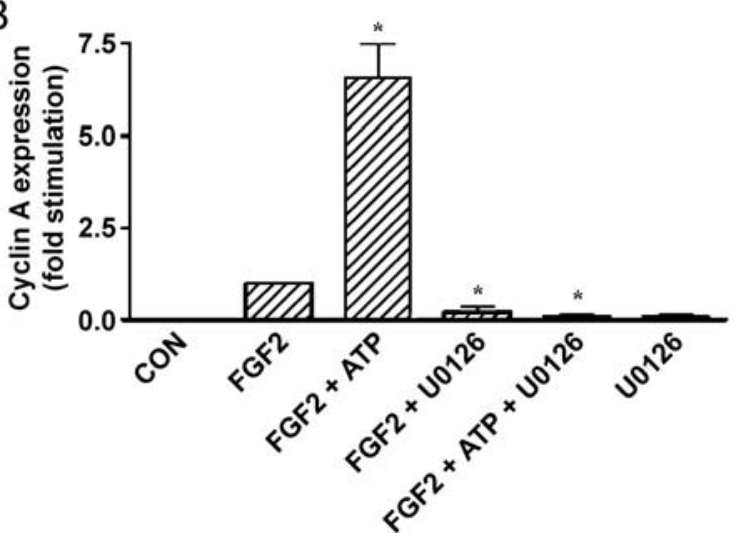

Figure 4. Blockade of the ERK cascade inhibits cyclin A expression induced by FGF2 and extracellular ATP. (A) U0126 (10 $\mu \mathrm{M}, 30 \mathrm{~min})$ was added to quiescent, primary cultures of rat cortical astrocytes prior to treatment with ATP $(100 \mu \mathrm{M})$, FGF2 $(25 \mathrm{ng} / \mathrm{ml})$ or a combination of ATP and FGF2 for $20 \mathrm{~h}$. Lysates were subjected to SDS-PAGE, and cyclin A expression was measured by immunoblotting. (B) Results (mean \pm SEM) from three independent experiments in which astrocyte cultures were treated as described in (A). Blockade of the ERK cascade significantly inhibited the expression of cyclin A induced by FGF2 as well as the potentiation of FGF2-induced cyclin A by extracellular ATP (*: FGF2 + ATP compared to FGF2, $P<0.001 ;$ FGF2 + U0126 compared to FGF2, $P<0.05 ; \mathrm{FGF} 2+\mathrm{ATP}+\mathrm{U} 0126$ compared to FGF2 + ATP, $P<0.001)$.

involved, we conducted studies with pyridoxalphosphate-6azophenyl-2' $4^{\prime}$ disulphonic acid (PPADS), an antagonist of UTP-stimulated, $\mathrm{P}_{2} \mathrm{Y}_{2}$ receptors in astrocytes [28, 29]. We found that when astrocytes were treated with $50 \mu \mathrm{M}$ PPADS 15 min prior to addition of UTP, DNA synthesis stimulated by UTP was reduced by $85 \%(n=3)$. We also investigated the effect of PPADS on the ability of UTP to enhance FGF2-induced mitogenesis but found that PPADS partially inhibited the mitogenic effect of FGF2 in the absence of UTP (data not shown), perhaps suggesting that basal extracellular nucleotides contribute to FGF2 mitogenic activity, as reported for other cellular responses [30]. Collectively, the effects of UTP on FGF2-induced cyclin expression and mitogenesis, together with the inhibitory effect of PPADS on UTP-stimulated DNA synthesis, suggest a role for $\mathrm{P} 2 \mathrm{Y}$ receptors, possibly $\mathrm{P}_{2} \mathrm{Y}_{2}$, in mediating the potentiating effects of extracellular nucleotides on FGF2 responses in astrocytes.

$\mathrm{P} 2 \mathrm{X}_{7}$ receptors have also been linked to cellular proliferation in a subpopulation of lymphoid cells [31] and in Jurkat cells [30], although activation of these ionotropic $\mathrm{P} 2 \mathrm{X}$ receptors can also lead to apoptosis in several cell types, including lymphocytes [33] and microglia [34]. Because functional $\mathrm{P} 2 \mathrm{X}_{7}$ receptors are expressed in astrocytes [35-38], we examined the effect of stimulating these receptors on FGF2-induced mitogenesis. We found
A

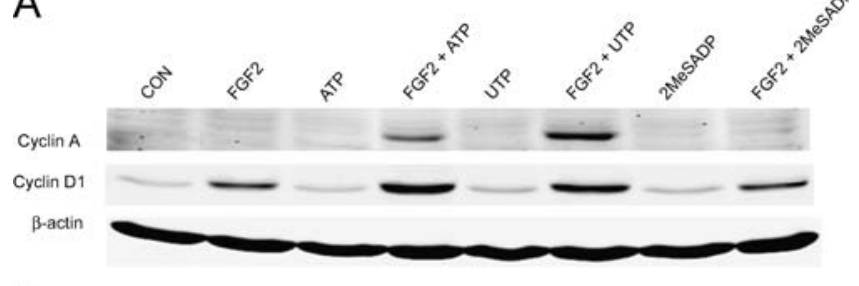

B

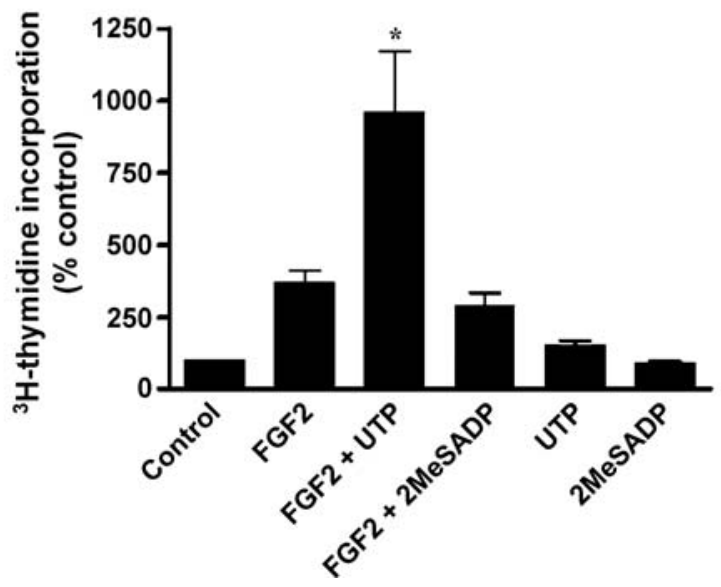

Figure 5. $\mathrm{P} 2 \mathrm{Y}$ purine/pyrimidines receptors mediate the synergistic effects of extracellular ATP on FGF2-induced cyclin expression and mitogenesis. (A) Quiescent, primary cultures of rat cortical astrocytes were treated with ATP $(100 \mu \mathrm{M})$ UTP $(100 \mu \mathrm{M})$, 2MeSADP $(10 \mu \mathrm{M})$, FGF2 $(25 \mathrm{ng} / \mathrm{ml})$ or a combination of nucleotides and FGF2 for $20 \mathrm{~h}$. Lysates were subjected to SDS-PAGE, and cyclin A expression was measured by immunoblotting. Blots were also probed with anti-actin antibodies as a loading control. UTP and ATP, but not 2MeSADP, potentiated the ability of FGF2 to stimulate expression of cyclin A. Similar results were obtained in three independent experiments. (B) Quiescent, primary cultures of rat cortical astrocytes were treated with ATP $(100 \mu \mathrm{M})$ UTP $(100 \mu \mathrm{M}), 2 \mathrm{MeSADP}(10 \mu \mathrm{M})$, FGF2 $(25 \mathrm{ng} / \mathrm{ml})$ or a combination of nucleotides and FGF2, and DNA synthesis was measured as described in Materials and methods. ${ }^{3} \mathrm{H}$-Thymidine incorporation in control cultures was $15,714 \pm 3568 \mathrm{cpm} / \mathrm{mg}$ protein (mean $\pm \mathrm{SEM} ; n=6$ ). FGF2-induced DNA synthesis was significantly enhanced by UTP $(* P<$ $0.05)$.

that activation of $\mathrm{P} 2 \mathrm{X}_{7}$ receptors by $2^{\prime}, 3^{\prime}-O$-(4-benzoyl)benzoyl-ATP (BzATP; $100 \mu \mathrm{M}$ ) reduced FGF2-induced mitogenesis by over $90 \%$ in primary cultures of rat cortical astrocytes (Figure 6). The decrease in DNA synthesis was not due to cytotoxicity as measured by trypan blue exclusion. For example, the percentage of trypan blue positive cells in cultures untreated or treated with $100 \mu \mathrm{M}$ BzATP, $25 \mathrm{ng} / \mathrm{ml}$ FGF2 or the combination of BzATP and FGF2 for $22 \mathrm{~h}$ did not exceed 6\%, whereas in cultures treated with staurosporine, approximately $75 \%$ of the cells were trypan blue positive after $22 \mathrm{~h}(n=3)$. Similar results were obtained with a tetrazolium-based test of cell viability (data not shown). Thus, the results presented here, together with those presented previously [20] suggest that $\mathrm{P} 2 \mathrm{Y}$ receptors and $\mathrm{P} 2 \mathrm{X}$ receptors exert opposing effects on FGF2-induced cellular proliferation in astrocyte cultures.

ERK signaling mediates proliferation and differentiation as well as growth arrest, depending on the duration and intensity of ERK activation [39, 40]. Because both P2Y and $\mathrm{P} 2 \mathrm{X}_{7}$ receptors are linked to ERK in astrocytes and 


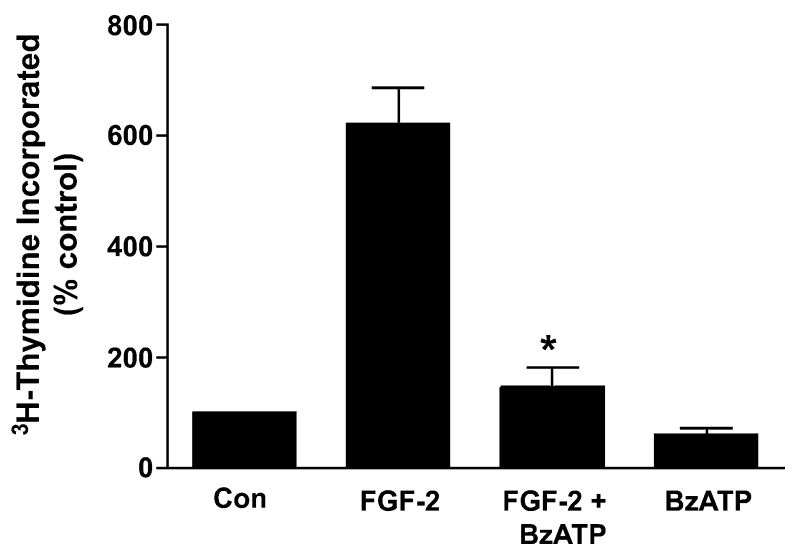

Figure 6. $\quad$ P2X receptors inhibit FGF2-induced mitogenesis in astrocytes. Quiescent, primary cultures of rat cortical astrocytes were treated with BzATP $(100 \mu \mathrm{M})$, FGF2 $(25 \mathrm{ng} / \mathrm{ml})$ or a combination of BzATP and FGF2, and DNA synthesis was measured as described in Materials and methods. FGF2-induced DNA synthesis was significantly inhibited by BzATP $(* P<0.001 ; n=6)$.

other cell types [24, 32, 35, 41, 42], we investigated the duration and intensity of ERK signaling stimulated by $\mathrm{P} 2 \mathrm{Y}$ and $\mathrm{P} 2 \mathrm{X}_{7}$ receptors in astrocytes. Astrocytes were treated with UTP $(100 \mu \mathrm{M})$ or BzATP $(100 \mu \mathrm{M})$ for 5, 30, 60, 120 , or $180 \mathrm{~min}$, and stimulation of ERK1/2 was determined by dual phosphorylation of threonine 202 and tyrosine 204 residues. We found that UTP stimulated strong ERK1/2 phosphorylation at $5 \mathrm{~min}$ which declined thereafter and returned to baseline after $120 \mathrm{~min}$; by contrast, BzATP stimulation of ERK1/2 was less intense at $5 \mathrm{~min}$ but remained elevated above baseline at $180 \mathrm{~min}$ (Figure 7). Quantification of data from this and an identical, independent experiment revealed that UTP stimulated an approximately 10-fold increase in ERK $1 / 2$ phosphorylation at $5 \mathrm{~min}$ as compared to about three-fold for BzATP, while at $3 \mathrm{~h}$, no stimulation was observed with UTP but approximately three-fold stimulation was maintained by BzATP. Thus, P2Y receptor activation led to an initially intense but transient activation of ERK whereas activation of ERK by $\mathrm{P} 2 \mathrm{X}$ receptors in astrocytes was initially less intense but more sustained. This finding is consistent with studies in other cells in which growth arrest is mediated by a sustained ERK signal whereas proliferation is linked to a transient ERK activation [39, 40].

\section{Discussion}

The major findings presented here are (1) extracellular ATP enhances the ability of FGF2 to induce the expression of cyclin D1 and cyclin A, cell cycle regulatory proteins involved in the entry and progression of mammalian cells through the G1 and S phases of the cell cycle, (2) the synergistic effects of extracellular ATP are mediated by signaling from $\mathrm{P} 2 \mathrm{Y}$ purine/pyrimidine receptors to ERK, and (3) stimulation of $\mathrm{P} 2 \mathrm{X}$ receptors inhibits the mitogenic activity of FGF2. These results may have implications regarding CNS development as well as reactive gliosis that occurs after CNS injuries.

Extracellular ATP has both short-term and long-term biological activities [43]. Of particular interest to nervous system development as well as CNS injury and repair is its ability to function as a trophic factor, either alone or as a co-mitogen in conjunction with polypeptide growth factors $[14,19]$. For example, Heppel and colleagues described synergistic interactions between extracellular ATP and growth factors such as EGF and PDGF in fibroblasts and neuroblastoma cell lines $[44,45]$. In astrocytes, we found that extracellular ATP markedly potentiated FGF2-induced mitogenesis [20]. However, little is known about the effects of extracellular ATP on cell cycle regulatory mechanisms, particularly in cells of the central nervous system. In a fibroblast cell line, extracellular ATP induced expression of cyclin A [46]. In mouse embryo and human fetus fibroblast cell lines in which placental alkaline phosphatase exerts growth factor-like effects, extracellular ATP potentiated the expression of cyclins A and E induced by placental alkaline phosphatase [47]. FGF2 is a mitogen for many, but not all, cell types. For example, in medial smooth muscle cells, FGF2 stimulated proliferation and expression of cyclin A, but in intimal smooth muscle cells, proliferation was only weakly stimulated by FGF2 and cyclin A expression was not induced [48]. Here we report for the first time that extracellular ATP enhances FGF2-induced expression of cyclins involved in cell cycle entry and progression through the G1 phase (cyclin D1) as well entry and progression through the $\mathrm{S}$ phase (cyclin A) of the cell cycle.

Our studies demonstrate that the increased expression of cyclin D1 and cyclin A induced by FGF2 and extracellular

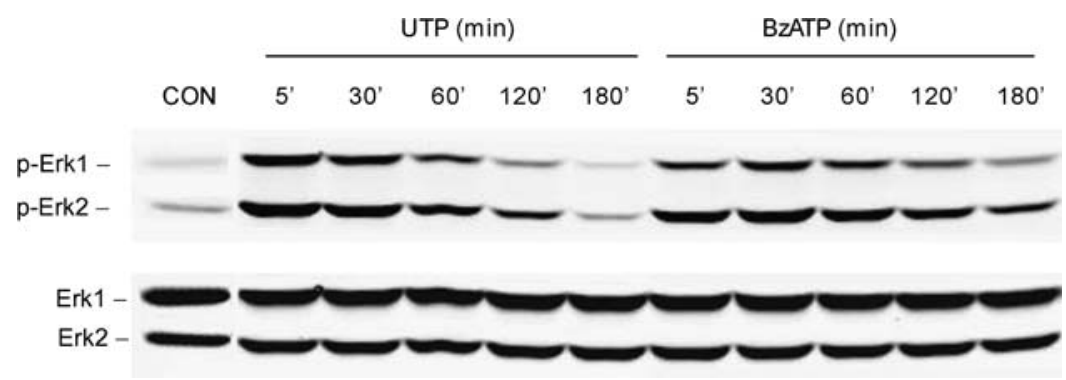

Figure 7. The duration and intensity of ERK phosphorylation differs between P2Y and P2X receptor signaling. Quiescent, primary cultures of rat cortical astrocytes were treated with UTP $(100 \mu \mathrm{M})$ or BzATP $(100 \mu \mathrm{M})$ for the times indicated. ERK1/2 phosphorylation was measured as described in Materials and methods. Stimulation of P2Y receptors with UTP elicited an intense but transient ERK phosphorylation whereas stimulation of P2X receptors with BzATP evoked an initially less intense but more sustained ERK phosphorylation. Similar results were obtained in an independent experiment. 
ATP involves ERK because cyclin expression was attenuated by blocking MEK, the upstream activator of ERK. These findings are consistent with those from studies in fibroblasts that demonstrate that up-regulation of cyclin D1 by PDGF was dependent on ERK activation [49]. Importantly, blockade of the ERK cascade also significantly inhibited the ability of extracellular ATP to enhance FGF2induced cyclin expression. These findings indicate that the ERK cascade plays an important role in mediating the comitogenic activity of extracellular ATP.

Our studies also indicate that $\mathrm{P} 2 \mathrm{Y}$ purine/pyrimidine receptors mediate the potentiating effects of extracellular nucleotides on FGF2-induced cyclin expression and astrocyte mitogenesis, whereas $\mathrm{P} 2 \mathrm{X}$ receptors, possibly the $\mathrm{P}_{2} \mathrm{X}_{7}$ subtype, inhibit the mitogenic activity of FGF2 in astrocytes. Previous studies demonstrated that rat cortical astrocytes express both $\mathrm{P} 2 \mathrm{Y}$ and $\mathrm{P} 2 \mathrm{X}$ receptors $[24,36$, 38]. For P2Y receptors, RT-PCR studies revealed that primary cultures of cortical astrocytes prepared from oneday-old rat pups contain P2Y1, P2Y2, P2Y4 receptors, but not P2Y6 receptors [24]. A more recent report indicated that $\mathrm{P} 2 \mathrm{Y} 6$ receptors are expressed in astrocytes prepared from seven-day-old rats [36]. Differences in subtype expression may be due to differences in developmental patterns of receptor expression or variations in culture conditions. Here we found that UTP, but not 2MeSADP, enhanced cyclin expression stimulated by FGF2. This finding is consistent with the observation that UTP enhanced the ability of FGF2 to stimulate DNA synthesis whereas 2MeSADP was ineffective. In addition, PPADS, an antagonist of UTP-stimulated, $\mathrm{P}_{2} \mathrm{Y}_{2}$ receptors in astrocytes [28, 29], attenuated DNA synthesis stimulated by UTP. Interestingly, PPADS also partially reduced FGF2 mitogenic activity in the absence of UTP. This may suggest cross-talk between $\mathrm{P}_{2} \mathrm{Y}_{2 / 4}$ receptors and FGF2 receptors, but further studies beyond the scope of this work are needed to investigate this possibility. Collectively, our results suggest that $\mathrm{P}_{2} \mathrm{Y}_{2}$ and/or $\mathrm{P}_{2} \mathrm{Y}_{4}$ receptors mediate the synergistic effects of extracellular nucleotides on FGF2-induced cyclin expression.

$\mathrm{P} 2 \mathrm{X}_{7}$ receptors are also expressed in cultured astrocytes $[35,36,38]$ and are coupled to ERK in these and other cells $[32,35,37]$. Functionally, cellular proliferation was observed upon expression of recombinant $\mathrm{P} 2 \mathrm{X}_{7}$ receptors in lymphoid cells lacking these receptors [31]. In addition, increased proliferation was also noted in Jurkat cells after stimulation of endogenous $\mathrm{P}_{2} \mathrm{X}_{7}$ receptors [32]. However, activation of $\mathrm{P}_{2} \mathrm{X}_{7}$ receptors leads to apoptosis in several cell types, including lymphocytes [33] and microglia [34]. Here we found that, in cultured astrocytes, the $\mathrm{P}_{2} \mathrm{X}_{7}$ receptor agonist BzATP inhibited the mitogenic activity of FGF2. Cytotoxicity experiments indicated that this was not due to a loss of cell viability. The opposing effects of $\mathrm{P} 2 \mathrm{X}$ and $\mathrm{P} 2 \mathrm{Y}$ receptor stimulation on FGF2-induced mitogenesis might be mediated at least in part by differences elicited in ERK responses. ERK can regulate cellular proliferation, differentiation or growth arrest, depending on the intensity and duration of the response and the cell type [50]. For example, in some cell types a sustained ERK signal is associated with growth arrest whereas a transient signal leads to proliferation [39, 40]. Consistent with this, here we found that stimulation of $\mathrm{P} 2 \mathrm{Y}$ receptors elicited an intense but transient ERK signal whereas that evoked by P2X receptors was initially weaker but more sustained. Further studies are needed to explore the effects of P2X receptors on cell cycle regulation and whether their inhibitory effects are due to the expression of cyclindependent protein kinase inhibitors.

Because FGF2 and ATP are increased after CNS injury and contribute to the gliotic response, the results presented here may be relevant to the hyperplasia observed in adult brains after trauma and stab wounds. The enhancement of FGF2-induced cyclin expression by extracellular ATP supports the suggestion of Nakatsuji and Miller [8] that changes in the expression of cell cycle regulatory proteins may be involved in the increase in astrocyte proliferation observed after injury to the adult CNS. The reactive astrocytes formed in injured CNS regions impact the reestablishment of neural connections and communication. Since reactive astrocytes produce a variety of molecules that can impede as well as promote axonal regeneration [51, 52], advances in our understanding of the mechanisms that mediate the formation of reactive astrocytes may offer an opportunity to enhance the beneficial, axonal growthpromoting features of reactive astrocytes while attenuating their harmful, growth-inhibiting properties. Thus, an understanding of the mechanisms leading to reactive astrocytes and the glial scar may provide new approaches to restore losses in motor skills and cognitive functions caused by CNS injury.

\section{Acknowledgements}

This work was supported by the National Institutes of Health (NS46651) and the Department of Veterans Affairs.

\section{References}

1. Cavanagh JB. The proliferation of astrocytes around a needle wound in the rat brain. J Anat 1970; 106: 471-87.

2. Latov N, Nilaver G, Zimmermann EA et al. Fibrillary astrocytes proliferate in response to brain injury: A study combining immunoperoxidase technique for glial fibrillary acidic protein and radioautography of tritiated thymidine. Dev Biol 1979; 72: 381-4.

3. Takamiya $\mathrm{Y}$, Koshsaka S, Toya $\mathrm{S}$ et al. Immunohistochemical studies on the proliferation of reactive astrocytes and the expression of cytoskeletal proteins following brain injury in rats. Dev Brain Res 1988; 38: 201-10.

4. Schiffer D, Giordana MT, Cavalla P et al. Immunohistochemistry of glial reaction after injury in the rat: Double stainings and markers of cell proliferation. Int J Dev Neurosci 1993; 11: 269-80.

5. Hill-Felberg SJ, McIntosh TK, Oliver DL et al. Concurrent loss and proliferation of astrocytes following lateral fluid percussion brain injury in the adult rat. J Neurosci Res 1999; 57: 271-9.

6. Norton WT. Cell reactions following acute brain injury: A review. Neurochem Res 1999; 24: 213-8.

7. Doetsch F, Caille I, Lim DA et al. Subventricular zone astrocytes are neural stem cells in the adult mammalian brain. Cell 1999; 97: 703-16. 
8. Nakatsuji Y, Miller RH. Density dependent modulation of cell cycle protein expression in astrocytes. J Neurosci Res 2001; 66: 487-96.

9. Sherr CJ. Mammalian G1 cyclins. Cell 1993; 73: 1059-65.

10. Finklestein SP, Apostolides PJ, Caday CG et al. Increased basic fibroblast growth factor (bFGF) immunoreactivity at the site of focal brain wounds. Brain Res 1988; 460: 253-9.

11. Perraud F, Labourdette G, Miehe $M$ et al. Comparison of the morphological effects of acidic and basic fibroblast growth factors on rat astroblasts in culture. J Neurosci Res 1988; 20: 1-11.

12. Eclancher F, Kehrli P, Labourdette G, Sensenbrenner M. Basic fibroblast growth factor (bFGF) injection activates the glial reaction in the injured adult rat brain. Brain Res 1996; 737: 201-14.

13. Hou YJ, Yu AC, Garcia JM et al. Astrogliosis in culture. IV. Effects of basic fibroblast growth factor. J Neurosci Res 1995; 40: 359-70.

14. Neary JT, Rathbone MP, Cattabeni F et al. Trophic actions of extracellular nucleotides and nucleosides on glial and neuronal cells. Trends Neurosci 1996; 19: 13-8.

15. Rathbone MP, Middlemiss PJ, Kim J-L et al. Adenosine and its nucleotides stimulate proliferation of chick astrocytes and human astrocytoma cells. Neurosci Res 1992; 13: 1-17.

16. Neary JT, Baker L, Jorgensen SL, Norenberg MD. Extracellular ATP induces stellation and increases GFAP content and DNA synthesis in primary astrocyte cultures. Acta Neuropathol 1994; 87: 8-13.

17. Abbracchio MP, Saffrey MJ, Hopker V, Burnstock G. Modulation of astroglial cell proliferation by analogues of adenosine and ATP in primary cultures of rat striatum. Neuroscience 1994; 59: 67-76.

18. Franke H, Krügel U, Illes P. P2 receptor-mediated proliferative effects on astrocytes in vivo. Glia 1999; 28: 190-200.

19. Neary JT, Abbracchio MP. Trophic roles of purines and pyrimidines In Williams M, Abbracchio MP (eds): Handbook of Experimental Pharmacology: Purinergic and Pyrimidergic Signalling. Berlin Heidelberg, New York: Springer 2001; 305-38.

20. Neary JT, Whittemore SR, Zhu Q, Norenberg MD. Synergistic activation of DNA synthesis in astrocytes by fibroblast growth factor and extracellular ATP. J Neurochem 1994; 63: 490-4.

21. Laemmli UK. Cleavage of structural proteins during the assembly of the head of bacteriophage T4. Nature 1970; 227: 680-5.

22. Peterson GL. Determination of total protein. Meth Enzymol 1983; 91: 95-119.

23. Seger R, Krebs EG. The MAPK signaling cascade. FASEB J 1995; 9: 726-35.

24. Lenz G, Gottfried C, Luo Z et al. P2Y purinoceptor subtypes recruit different MEK activators in astrocytes. Br J Pharmacol 2000; 129: 927-36.

25. Zhu Q, Neary JT. Signaling by ATP receptors in astrocytes. NeuroReport 1994; 5: 1617-20.

26. Lenz G, Goncalves D, Luo Z et al. Extracellular ATP stimulates an inhibitory pathway towards growth factor-induced cRaf-1 and MEKK activation in astrocyte cultures. J Neurochem 2001; 77: 1001-9.

27. Neary JT, Kang Y, Bu Y et al. Mitogenic signaling by ATP/P2Y purinergic receptors in astrocytes: Involvement of a calciumindependent protein kinase $\mathrm{C}$, extracellular signal regulated protein kinase pathway distinct from the phosphatidylinositolspecific phospholipase C, calcium pathway. J Neurosci 1999; 19: 4211-20.

28. Ho C, Hicks J, Salter MW. A novel P2-purinoceptor expressed by a subpopulation of astrocytes from the dorsal spinal cord of the rat. Br J Pharmacol 1995; 116: 2909-18.

29. Gallagher CJ, Salter MW. Differential properties of astrocyte calcium waves mediated by $\mathrm{P} 2 \mathrm{Y} 1$ and $\mathrm{P} 2 \mathrm{Y} 2$ receptors. J Neurosci 2003; 23: 6728-39.

30. Ostrom RS, Gregorian C, Insel PA. Cellular release of and response to ATP as key determinants of the set-point of signal transduction pathways. J Biol Chem 2000; 275: 11735-9.

31. Baricordi OR, Melchiorri L, Adinolfi E et al. Increased proliferation rate of lymphoid cells transfected with the P2X7 ATP receptor. J Biol Chem 1999; 274: 33206-8.

32. Budagian V, Bulanova E, Brovko L et al. Signaling through P2X7 receptor in human $\mathrm{T}$ cells involves p561ck, MAP kinases, and transcription factors AP-1 and NF-kappa B. J Biol Chem 2003; 278: 1549-60.

33. Zanovello P, Bronte V, Rosato A et al. Responses of mouse lymphocytes to extracellular ATP. II. Extracellular ATP causes cell type-dependent lysis and DNA fragmentation. J Immunol 1990; 145: 1545-50.

34. Ferrari D, Chiozzi P, Falzoni S et al. ATP-mediated cytotoxicity in microglial cells. Neuropharmacol 1997; 36: 1295-1301.

35. Panenka W, Jijon H, Herx LM et al. P2X7-like receptor activation in astrocytes increases chemokine monocyte chemoattractant protein-1 expression via mitogen-activated protein kinase. J Neurosci 2001; 21: 7135-42.

36. Fumagalli M, Brambilla R, D'Ambrosi N et al. Nucleotide-mediated calcium signaling in rat cortical astrocytes: Role of P2X and P2Y receptors. Glia 2003; 43: 218-03.

37. Gendron FP, Newbold NL, Vivas-Mejia PE et al. Signal transduction pathways for $\mathrm{P} 2 \mathrm{Y} 2$ and $\mathrm{P} 2 \mathrm{X} 7$ nucleotide receptors that mediate neuroinflammatory responses in astrocytes and microglial cells. Biomed Res 2003; 14: 47-61.

38. Jacques-Silva MC, Rodnight $\mathrm{R}$, Lenz $\mathrm{G}$ et al. P2X7 receptors stimulate Akt phosphorylation in astrocytes. Br J Pharmacol 2004; 141: $1107-18$.

39. Marshall CJ. Specificity of receptor tyrosine kinase signaling: Transient versus sustained extracellular signal-regulated kinase activation. Cell 1995; 80: 179-85.

40. Tombes RM, Auer KL, Mikkelsen R et al. The mitogen-activated protein (MAP) kinase cascade can either stimulate or inhibit DNA synthesis in primary cultures of rat hepatocytes depending upon whether its activation is acute/phasic or chronic. Biochem J 1998; 330: $1451-60$.

41. King BF, Neary JT, Zhu Q et al. P2 purinoceptors in rat cortical astrocytes: Expression, calcium-imaging and signalling studies. Neurosci 1996; 74: 1187-96.

42. Gendron FP, Neary JT, Theiss PA et al. Mechanisms of P2X7 receptor-mediated ERK1/2 phosphorylation in human astrocytoma cells. Am J Physiol, Cell Physiol 2003; 284: X571-81.

43. Burnstock G. Overview: Purinergic mechanisms. Ann N Y Acad Sci 1990; 603: 1-18.

44. Huang N, Wang D, Heppel LA. Extracellular ATP is a mitogen for 3T3, 3T6, and A431 cells and acts synergistically with other growth factors. Proc Natl Acad Sci USA 1989; 86: 7904-8.

45. Wang D, Huang N-N, Heppel LA. Extracellular ATP shows synergistic enhancement of DNA synthesis when combined with agents that are active in wound healing or as neurotransmitters. Biochem Biophys Res Commun 1990; 166: 251-8.

46. Yang JJ, Krauss RS. Extracellular ATP induces anchoragedependent expression of cyclin A and rescues the transformed phenotype of a ras-resistant mutant cell line. J Biol Chem 1997; 272: 3103-8.

47. She QB, Mukherjee JJ, Chung T, Kiss Z. Placental alkaline phosphatase, insulin, and adenine nucleotides or adenosine synergistically promote long-term survival of serum-starved mouse embryo and human fetus fibroblasts. Cell Signal 2000; 12: 659-65.

48. Olson NE, Kozlowski J, Reidy MA. Proliferation of intimal smooth muscle cells: Attenuation of basic fibroblast growth factor 2-stimulated proliferation is associated with increased expression of cell cycle inhibitors. J Biol Chem 2000; 275: 11270-7.

49. Weber JD, Raben DM, Phillips PJ, Baldassare JJ. Sustained activation of extracellular signal regulated kinase 1 (ERK1) is required for the continued expression of cyclin D1 in G1 phase. Biochem J 1997; 326: 61-8.

50. Roovers K, Assoian RK. Integrating the MAP kinase signal into the G1 phase cell cycle machinery. BioEssays 2000; 22: 818-826.

51. Ridet JL, Malhotra SK, Privat A, Gage FH. Reactive astrocytes: Cellular and molecular cues to biological function. Trends Neurosci 1997; 20: 570-7.

52. Silver J, Miller JH. Regeneration beyond the glial scar. Nat Rev, Neurosci 2004; 5: 146-56. 